\title{
REFLEXÕES SOBRE UMA EXPERIÊNCIA PEDAGÓGICA A PARTIR DAS NARRATIVAS (AUTO)BIOGRÁFICAS
}

\section{MARCELO SILVA DA SILVA}

https://orcid.org/0000-0003-2516-1583

Universidade Federal do Paraná Setor Litoral

RESUMO O artigo aborda de forma reflexiva o estudo sobre a prática pedagógica desenvolvida no curso de licenciatura em Educação Física da Universidade Federal do Paraná (UFPR)- Setor Litoral, no módulo de Projeto de Aprendizagem. O objetivo do trabalho foi construir uma prática pedagógica de pesquisa-formação com a utilização das narrativas (auto)biográficas como estratégia de ensino e pesquisaformação dos sujeitos do processo, além de identificar elementos significativos das trajetórias dos estudantes ingressantes no curso, que pudessem indicar os motivos da escolha do curso e as afinidades destes com a profissão de professor de Educação Física. 0 texto apresenta elementos teóricos sobre as narrativas (auto)biográficas enquanto metodologia de pesquisa e de formação, descreve a trajetória e estratégias adotadas no processo das aulas-pesquisa e implementação da proposta, aponta alguns resultados encontrados sobre os estudantes participantes e sobre o processo em si como possibilidade pedagógica para uma prática significativa de formação de futuros professores.

Palavras-chave: Narrativas (Auto)biográficas. Formação de Professores. Docência Universitária.

\section{ABSTRACT REFLECTIONS ON THE PEDAGOGICAL EXPERIENCE FROM (AUTO)BIOGRAPHIC NARRATIVES}

This paper reflectively addresses the study of the pedagogical practice developed in the Physical Education licentiate course at the Federal University of Paraná (UFPR) Coast Sector, during the Learning Project module. The goal of this study was to build a pedagogical practice of research-training through (auto)biographic narratives as a strategy for teaching and research-training of the subjects involved in the process, in addition to identifying significant elements in the new students' histories which could indicate their reasons for having chosen the course and their affinities with the Physical Education 
teacher profession. This article presents theoretical elements about (auto)biographical narratives as research and training methodology and describes the journey and the strategies adopted for the class-research process and implementation of the project. Moreover, it points to some results found regarding the participants and about the process itself as a pedagogical possibility for a meaningful practice for further qualifying future teachers.

Keywords: (Auto)biographic Narratives. Teacher Training. University Teaching Practice.

\section{RESUMEN REFLEXIONES SOBRE UNA EXPERIENCIA PEDAGÓGICA DESARROLLADA CON NARRATIVAS (AUTO) BIOGRÁFICAS}

El artículo presenta de manera reflexiva el estudio sobre la práctica pedagógica desarrollada en la carrera de Educación Física de la Universidad Federal de Paraná (UFPR)- Sector Litoral, en el módulo Proyecto de aprendizaje. El objetivo de este trabajo fue construir una práctica pedagógica de formación y investigación utilizando las narraciones (auto) biográficas como estrategia de enseñanza, formación y investigación de los sujetos del proceso, identificando elementos significativos de las trayectorias de los estudiantes que podrían indicar las razones para elegir el curso y sus afinidades con la profesión de profesor de Educación Física. El texto presenta elementos teóricos sobre narraciones (auto)biográficas como metodología de investigación y formación, describe la trayectoria y las estrategias adoptadas en el proceso de investigación de clase y la implementación de la propuesta, señala algunos resultados encontrados sobre los estudiantes participantes y sobre el proceso en sí misma como una posibilidad pedagógica para una práctica significativa de formación de futuros docentes.

Palabras clave: Narrativas (auto)biográficas. Formación de profesores. Docencia universitaria. 


\section{Um instante introdutório}

$\mathrm{Na}$ entrada da estação, avisou que faltavam 30 minutos. De repente lembrou-se que num café na Rua Brasil (a poucos metros da casa de Yrigoyen) havia um gato enorme que se deixava acariciar pelas pessoas, como uma divindade desdenhosa. Ele entrou. Ali estava o gato, adormecido. Pediu uma chávena de café, adoçou-a lentamente, provou-a (esse prazer tinha-lhe sido proibido na clínica) e pensou, enquanto alisava o pelo preto, que esse contacto era ilusório e que eram como que separados por um copo, porque o homem vive no tempo, na sucessão, e o animal mágico, no presente, na eternidade do instante. (BORGES, 1998, p. 209, tradução nossa) ${ }^{1}$

A eternidade do instante, postulada por Borges (1998), nos remete a pensar o tempo vivido no momento, mas cabe perguntar: sabemos viver o instante? Conseguimos perceber a eternidade contida no tempo presente? Sem pensarmos na sucessão, no contínuo, no que esta por vir?

Esse questionamento inicia o texto para nos provocar sobre a riqueza de sensações, produções, conhecimentos, que criamos e recriamos a cada instante em nosso ser-fazer docente, mas que, em geral, se perde na sucessão do tempo vivido e não ressignificado. "Navegar é preciso, viver não é preciso", citaria o poeta, talvez devemos navegar, nos aventurar, por que somente viver pode ser algo pequeno para nossa alma, mas, ao mesmo tempo, sabemos que viver não é algo preciso, ao contrário, envolve riscos, desvios, imprecisões, emoções, que de certa forma é o que nos torna seres humanos.

1 "En el hall de la estación advirtió que faltaban treinta minutos. Recordó bruscamente que en un café de la calle Brasil (a pocos metros de la casa de Yrigoyen) había un enorme gato que se dejaba acariciar por la gente, como una divinidad desdeñosa. Entró. Ahí estaba el gato, dormido. Pidió una taza de café, la endulzó lentamente, la probó (ese placer le había sido vedado en la clínica) y pensó, mientras alisaba el negro pelaje, que aquel contacto era ilusorio y que estaban como separados por un cristal, porque el hombre vive en el tiempo, en la sucesión, y el mágico animal, en la actualidad, en la eternidad del instante".
Nesse conjunto de instantes, quando criamos e recriamos nosso viver e nosso ser-fazer docente, está a riqueza de nossa prática, que pode ser uma práxis, se refletirmos sobre ela, se a problematizarmos de diferentes maneiras, buscando navegar em nossas descobertas, sabendo que viver é se arriscar.

Nesse processo de arriscar e criar, pensar e repensar a prática, desenvolvemos na docência universitária uma experiência no sentido que Bondía (2002) destaca, como algo que nos toca, algo que nos acontece, que nos atravessa, que nos transforma, uma experiência significativa, mediante a qual buscamos produzir uma práxis focada nos sujeitos do processo. 0 presente texto descreve alguns dos caminhos e estratégias percorridos, bem como as descobertas e resultados da investigação proposta.

\section{Ser-fazer docente entre fronteiras}

Bachelard (2007) em sua obra A Intuição do Instante, afirma que:

A poesia é uma metafísica instantânea. Num curto poema, ela deve dar uma visão do universo e o segredo de uma alma, um ser e objetos, tudo ao mesmo tempo. Se segue simplesmente o tempo da vida, ela é menos que esta; só pode ser mais que a vida imobilizando-a, vivendo no próprio lugar a dialética das alegrias e das dores. Ela é, então, o princípio de uma simultaneidade essencial em que o ser mais disperso, mais desunido, conquista sua unidade. (p. 99)

Se a poesia é capaz de capturar o universo e o segredo de uma alma, vivendo na dialética das alegrias e das dores, talvez possamos, metaforicamente, entender o fazer docente como um fazer poético, pois o docente precisa transitar entre um universo de saberes, ao mesmo tempo que tenta tocar a essência dos sujeitos, levando-os a viver a dialética do ensinar e aprender, processo que envolve alegrias e dores. 
Ser docente é pensar para além de suas necessidades, é tentar transformar o que the é mais caro em algo que possa ser digerido, assimilado, processado pelo outro, é problematizar constantemente o que fazemos e por que fazemos, tentando levar o outro para este lugar da dúvida, muito mais do que da certeza.

o docente, ao realizar o seu trabalho, ao mesmo tempo em que produz a sua existência, essa também o modifica, como afirma Charlot (2000, p. 54), “a educação é uma produção de si por si mesmo, mas essa autoprodução só é possivel pela mediação do outro e com sua ajuda". Nesse sentido, a produção das (auto) biografias e as reflexões que possibilitam pode tornar-se um excelente dispositivo de formação reflexiva para o docente e os estudantes.

Mas ser docente não é uma tarefa fácil, pois implica dispor-se a uma entrega com o outro, para que nessa relação, nessa mediação entre docente, conhecimento e estudante, se possa efetivar o ato de ensinar e aprender, processo que não se dá sem conflitos, sem dores, mas também, não acontece sem alegrias.

Por esse caminho, vou aventurando-me, buscando refletir, a partir da sistematização das experiências vividas e apreendidas no serfazer docente, tecendo dos fios da memória e registros das práticas, uma tela que tem como paisagem os riscos e desafios da docência universitária.

Refiro-me, aqui, a uma docência produzida, muitas vezes, na tentativa de transitar entre fronteiras, entre as linhas que delimitam o conhecimento fundado na ciência moderna, que sendo "um conhecimento disciplinar, tende a ser um conhecimento disciplinado, isto é, segrega uma organização do saber orientada para policiar as fronteiras entre as disciplinas e reprimir os que as quiserem transpor" (SOUZA SANTOS, 1995, p. 46).

A busca por ser docente em um paradigma emergente, segundo o qual o conhecimento é total, mas sendo total, é também local (SOUSA SANTOS, 1995), constitui-se ao redor de temas que, em dado momento, são adaptados por grupos sociais concretos como projetos de vida locais.

O conhecimento, no paradigma emergente, busca superar a separação sujeito/objeto, consagrada pela ciência moderna, através da visão do homem como sujeito epistêmico, mas o expulsando como sujeito empírico (SOUSA SANTOS, 2002). Nesse novo paradigma, todo conhecimento é autoconhecimento. Dessa maneira, o pesquisador não descobre, ele cria conhecimentos e os "pressupostos metafísicos, os sistemas de crenças, os juízos de valor, não estão antes nem depois da explicação científica da natureza ou da sociedade. São partes integrantes dessa mesma explicação" (SOUSA SANTOS, 2002, p. 83). Assim, "no paradigma emergente, o caráter autobiográfico do conhecimento-emancipação é plenamente assumido: um conhecimento compreensivo e íntimo que não nos separe e antes nos una pessoalmente ao que estudamos". (SOUSA SANTOS, 2002, p. 84)

Por ser, nessa perspectiva, um conhecimento de caráter autobiográfico, compreensivo e íntimo, o fazer docente que se fundamentasse neste, busca transgredir as fronteiras e nos leva a pensar de forma sensivel sobre o que vivemos, sobre o que são as linhas que nos separam, ou aproximam, na relação docente-estudante, ensinar-aprender, conhecimento-autoconhecimento, espaço-lugar, entre outras fronteiras.

Ao pensar as fronteiras que criamos e nos definem, podemos descrevê-las na forma da linguagem poética, sintética e sem preâmbulos, como Bachelard (2007) define em sua reflexão:

2 "Enquanto todas as demais experiências metafísicas são preparadas em intermináveis prólogos, a poesia recusa os preâmbulos, os princípios, os métodos, as provas. Recusa a dúvida. Quanto muito, ela tem necessidade de um prelúdio de silêncio. Primeiro, valendo-se de palavras ocas, ela faz calar a prosa ou os trinados que deixariam na alma do leitor uma con- 
Estou aqui
me sinto como se estivesse
no começo
do fim
um sentimento ambíguo
de quem às vezes
não se reconhece
estou aqui
no fim de algum lugar
ou no começo de outro
estou em uma fronteira,
mas as fronteiras
nem sempre são o fim
nem mesmo o começo
podem ser meio,
um meio de nos conhecermos

a que servem

as fronteiras?

a quem servem as fronteiras?

nossa identidade

está entre linhas?

entre cores e sabores?

entre credos?

raças e etnias?

o que nos constitui?

estou aqui

na fronteira

diante do outro

diante do lugar

diante de você

diante do outro

com meu diferente

e com meu igual

O fazer docente se encontra nesse lugar de fronteira, próximo e ao mesmo tempo distante, separado por linhas que nos unem, reconhecendo as diferenças entre os sujeitos, buscando construir a partir das contradições, valorizando o local sem perder de vista o global, assim penso a docência, não somente por uma intuição ou sensação, mas a partir das experiências vividas na docência.

tinuidade de pensamento ou de murmúrio. Depois, após as sonoridades vazias, ela produz seu instante." (BACHELARD, 2007, p. 100)
Ao entender a experiência como significativa no processo de formação e construção do conhecimento, não desconsideramos o papel e valor da ciência ou do conhecimento científico, ao contrário, valorizamos esse conhecimento, mas entendemos que as explicações científicas são descrições metódicas e detalhadas de uma experiência vivida, pois "o que explicamos é sempre uma experiência. Por isso, quem descreve o que vai explicar, descreve o que se tem de fazer para ter a experiência que se quer explicar" (MATURANA, 2002, p. 55).

Para Maturana, a ciência - e a validade das explicações científicas - "não se constitui nem se funda na referência a uma realidade independente que se possa controlar, mas na construção de um mundo de ações comensurável com nosso viver" (2002, p. 55).

Mundo de ações este que, construído em nossas práticas, pode se constituir em um conhecimento valido e importante que precisa ser reconhecido e valorizado, mas também, problematizado. Nesse intuito, ao escrever este texto busquei relatar, reconhecer, valorizar e, principalmente, problematizar a prática vivida.

\section{As narrativas biográficas como possibilidade do ser-fazer docente}

Ao longo da trajetória como docente universitário, busco encontrar estratégias e metodologias que fossem significativas, não só quanto às possibilidades didáticas, mas também quanto ao potencial formador para os sujeitos do processo, que impactassem na construção de novos projetos de formação e vida. Entre diferentes experiências com métodos e propostas diversas, percebemos que para tornar o processo de ensino e aprendizagem significativo, do ponto de vista da formação de novos professores, o resgate dos próprios sujeitos 
como protagonistas deste processo era fundamental, o que nos levou ao encontro do método (auto)biográfico.

A escolha pelo resgate dos elementos (auto) biográficos surge ao dialogar com Josso (1999, p. 13), quando afirma que o "fascínio com relação à perspectiva biográfica parece inseparável da reabilitação progressiva do sujeito e do ator", atitude que se coloca como imperativa ao tentar pensar os processos formativos de estudantes do curso de licenciatura em Educação Física.

A apreciação e o vínculo com o método (auto)biográfico vão se fortalecendo a partir do estudo de autores e da produção sobre o tema que apresentou um significativo crescimento nas décadas de 1990, 2000 e 2010 no campo da Educação. Venâncio \& Sanches Neto (2019, p. 731) destacam que no "âmbito da Educação Física brasileira, tem havido crescente valorização das narrativas como modo de compreensão situada dos contextos educacionais escolares".

Venâncio \& Sanches Neto (2019) sistematizam sobre a importância das narrativas nos estudos da Educação Física, na formação inicial e continuada de professores, elencando estudos e autores que têm utilizado desse método como proposta de formação e pesquisa, ressaltando que a incorporação dos escritos (auto)biográficos contribuem para retomada da subjetividade na epistemologia da prática.

Assim, a escolha das narrativas como dispositivo de formação, que parte do exercício de rememoração, é o componente essencial na construção/reconstrução da subjetividade e, também, da construção dos elementos de análise para compreensão dos objetos de estudo do pesquisador.

A pesquisa (auto)biográfica é uma forma de história auto-referente, portanto plena de significado, em que o sujeito se desvela, para si, e se revela para os demais. [...] A pesquisa (auto) biográfica, embora se utilize de diversas fontes, tais como narrativas, história oral, epístolas fotos, vídeos, filmes, documentos, utiliza-se do exercício da rememoração, por excelência. Esta é componente essencial na característica do (a) narrador (a) na construção/reconstrução de sua subjetividade. Esta também é componente essencial com que o pesquisador trabalha para poder (re)construir elementos de análise que possam auxiliá-lo na compreensão de seu objeto de estudo, ao tentar articular memória e conhecimento, procurando edificar uma 'arqueologia da memória'. (ABRAHÃO, 2004, p. 202)

Trabalhar com memórias, narrativas de vida, narrativas (auto)biográficas é uma possibilidade singular de descrever e problematizar um mundo de ações, a partir do olhar dos diferentes sujeitos envolvidos, resgatando as subjetividades sem perder a objetividade necessária ao estudo acadêmico. Além disso,

[...] a especificidade do método biográfico implica um 'ir além' do quadro lógico formal e do modelo mecânico característico da epistemologia científica estabelecida. Se queremos fazer uso sociológico do potencial heurístico da biografia sem roubar as suas características essenciais (subjectividade, historicidade), temos de nos projectar para além do quadro da epistemologia clássica. Devemos considerar as bases epistemológicas do método biográfico na sua extensão, como uma forma de raciocínio dialéctico capaz de compreender a práxis sintética recíproca que rege a interacção entre um indivíduo e um sistema social. (FERRAROTTI, 1993, p. 122, tradução nossa) ${ }^{3}$

Nessa perspectiva, as narrativas ajudam na escrita das trajetórias e histórias vividas e,

3 “[...] la especifidad del método biográfico implica un 'ir más allá' del marco lógico formal y del modelo mecánico característico de la epistemología científica establecida. Si queremos hacer un uso sociológico del potencial heurístico de la biografia sin hurtar sus características esenciales (subjetividad, historicidad), debemos proyectarnos a nosotros mismos más allá del marco de la epistemología clásica. Debemos considerar las bases epistemológicas del método biográfico en su extensión, como una forma de razón dialéctica capaz de comprender la praxis sintética reciproca que gobierna la interacción entre un individuo y un sistema social". 
também, são um elemento de retorno às experiências e vivências formativas, levando a um processo reflexivo, fundamental à produção de conhecimentos e atuação docente e base desse resgate do sujeito ator.

No âmbito da Educação Física, Neira (2017) aponta que:

As narrativas estimulam a reflexão sobre a própria ação, sobretudo quando são analisadas de modo coletivo por professores(as) em diferentes estágios da carreira docente. No caso da formação inicial, Neira (2017) aponta a ocorrência de discussões sobre situações de aprendizagem, a mobilização de conceitos que fundamentam as intervenções e a análise das experiências individuais. Essas atividades posicionam os(as) estudantes em situações que demandam a reflexão e a busca por alternativas para o encaminhamento de problemas compartilhados entre os(as) colegas. (NEIRA, 2017, citado por VENÂNCIO \& SANCHES NETO, 2019, p. 733)

Processo reflexivo esse que pode potencializar a construção da identidade docente. Como observa Abrahão,

[...] o processo reflexivo tem em Giddens (2002) um teórico que enfatiza a reflexão e a construção de identidade no seio do que denomina de o surgimento da política-vida, como política de realização do eu que vem de encontro à ameaça de falta de sentido pessoal no contexto global da 'segunda modernidade' ou modernidade tardia. Nesse contexto, a produção de sentido pessoal tem na construção da auto identidade, segundo o autor 'um empreendimento reflexivamente organizado' (op. cit. p.197-198): o projeto reflexivo do eu. (ABRAHÃO, 2016, p. 29-30, grifos da autora)

Esta produção reflexiva do eu nos remete para a potencialidade do método (auto)biográfico para além da pesquisa, passando a fazer parte da prática pedagógica construída na docência universitária, como um método de formação ou pesquisa formação.

A questão da indissociabilidade do eu pessoal do eu profissional remete à dimensão que se ocupa da construção da identidade nessa área, isto é, de sentir-se e de ser professor. Segundo Derouet (1988) a identidade profissional de professores é uma elaboração que perpassa a vida profissional em diferentes e sucessivas fases, desde a opção pela profissão, passando pela formação inicial e, de resto, por toda a trajetória profissional, construindo-se com base nas experiências, nas opções, nas praticas, nas continuidades e descontinuidades, tanto no que diz respeito às representações, como no que se refere ao trabalho concreto. (ABRAHÃO, 2016, p. 30)

Assim, as narrativas (auto)biográficas originam processos de pesquisa, bem como processos de formação. Partindo desse pressuposto, desenvolvemos nos últimos anos, uma experiência pedagógica que consideramos significativa e passivel de ser relatada e analisada criticamente.

\section{Narrando o vivido: a experiência dos Projetos de Aprendizagem}

A proposição fundamental do trabalho de investigação/formação realizado foi baseada na perspectiva de que a construção de saberes necessários ao processo de formação e futura atuação profissional dos egressos da universidade não se resume aos saberes acadêmicos/ profissionais e estão profundamente determinados, ou influenciados, pelas experiências de vida dos sujeitos, anteriores ao processo de formação inicial na graduação, assim, o objetivo do trabalho-pesquisa desenvolvido foi: possibilitar que os próprios estudantes encontrassem referências em suas narrativas de vida que dessem sentidos e significados para a escolha do curso de licenciatura, identificando possiveis projetos de formação ao longo da graduação.

Penso que o processo de formação inicial dos futuros professores pode se utilizar de estratégias de documentação narrativa das 
experiências vividas, como já observado anteriormente nos estudos citados, à medida que entendo que:

[...] a documentação narrativa das experiências pedagógicas faz parte do campo da investigação pedagógica como uma modalidade particular de investigação interpretativa que procura reconstruir, documentar, sublinhar e criticar os significados, compreensões e interpretações pedagógicas que os professores constroem, reconstróem e negociam quando escrevem, lêem, reflectem e falam entre colegas sobre as suas próprias práticas educativas. (SUÁREZ, 2008, p. 11 , tradução nossa) ${ }^{4}$

Em nosso caso, da mesma forma como os professores no contexto da atuação podem dar sentidos e significados às suas práticas à medida em que escrevem, leem e refletem sobre elas, os estudantes em formação podem, através da documentação de suas narrativas, produzirem processos de aprendizados significativos ao longo da graduação.

Descrever sinteticamente esse processo pode parecer ser algo simples ou trivial, mas ao tentar efetivamente construir algo novo, desafiador, até inovador, em um contexto não favorável ou receptivo, seja por parte dos estudantes, seja por parte dos próprios colegas de docência, ou pelas questões burocrático -administrativas, é preciso ter claro que estamos "entrando pela toca do coelho", ao mesmo tempo que encontramos coisas maravilhosas, nos deparamos com outras não tão boas.

O trabalho construído na pesquisa situase no campo da investigação-ação da própria prática docente. Nessa perspectiva, o processo metodológico vem sendo elaborado a partir

4 [...] la documentación narrativa de experiencias pedagógicas se inscribe en el campo de la investigación educativa como una modalidad particular de indagación interpretativa que pretende reconstruir, documentar, tensionar y volver críticos los sentidos, comprensiones e interpretaciones pedagógicas que los docentes construyen, reconstruyen y negocian cuando escriben, leen, reflexionan y conversan entre colegas acerca de sus propias prácticas educativas. de diferentes experiências educativas no ensino superior, assim, é possivel dizer que não há uma metodologia, mas metodologias, que foram lapidadas ao longo de uma trajetória docente. Descrevo aqui o trabalho realizado no primeiro semestre de 2015 , com a turma ingressante de licenciatura em Educação Física.

Procurei caracterizar a metodologia como uma pesquisa-ação, ou pesquisa-formação na perspectiva de Josso (1999; 2004), não apresentando objetivos iniciais totalmente definidos, visando serem complementados e alterados, à medida que o processo foi implementado com os estudantes.

As principais etapas e a forma como o trabalho está organizado, parte de uma aproximação com as etapas propostas por Josso (2004) para o trabalho de pesquisa-formação: fase de introdução à construção da narrativa da história de formação; fase da elaboração das narrativas; fase de trabalho coletivo com as narrativas; fase do acordo; fase de compreensão e de interpretação das narrativas; fase de balanço dos formadores e dos participantes.

Nossas etapas foram organizadas da seguinte forma: a) fase de introdução, no início do semestre são apresentados aos estudantes, elementos introdutórios sobre a teoria do método (auto)biográfico, na sequência são convidados a participar do processo, concordando com um acordo/contrato pedagógico; b) fase da escrita da narrativa, a partir de uma dinâmica inicial, os estudantes realizam um primeiro exercício de escrita, elaborando um breve resumo sobre suas trajetórias de vida até aquele momento; na sequência, retomei os elementos teóricos sobre o método (auto)biográfico, possibilitando a reescrita das trajetórias de vida, de maneira ampliada, tendo como referência questões provocativas, previamente elaboradas pelo docente; c) fase do trabalho coletivo, com essa escrita em mãos, partimos para o processo de mapeamento de palavras-chave, 
considerando os objetivos do módulo e construídos coletivamente durante as etapas iniciais (essa etapa é realizada individualmente, cada estudante a partir da sua escrita); d) fase de compreensão, desse mapeamento, procurei sistematizar coletivamente as falas/passagens significativas para construir uma sistematização em categorias (construídas a partir dos objetivos definidos); e) fase de balanço, após essa sistematização, parti para uma etapa final, momento em que discutimos o que foi encontrado no processo e, principalmente, como esse processo de rememorar, resgatar as experiências vividas pode dar sentidos e significados para o momento que estão vivendo e as suas escolhas na continuidade do processo de formação.

Após finalizar essas etapas, os resultados produzidos são registrados de diferentes formas e ficam arquivados com o docente para um diálogo futuro com os estudantes.

Para situar os objetivos e o processo desenvolvido na formação dos estudantes, é preciso entender alguns elementos sobre o curso em questão. A licenciatura em Educação Física do Setor Litoral da Universidade Federal do Paraná (UFPR) é um curso novo, criado em 2014, e com a primeira turma ingressando em 2015, possui em seu Projeto Pedagógico de Curso, assim como os demais do referido setor, três eixos centrais que definem seu formato e grade curricular, os eixos são: as Interações Culturais e Humanísticas (ICHs), correspondendo a $20 \%$ da carga horária do curso; os Fundamentos Teórico Práticos (FTPs), com 60\% da carga horária do curso; e os Projetos de Aprendizagem (PAs), com $20 \%$ da carga horária do curso.

0 módulo, ${ }^{5}$ no qual a pesquisa-formação foi desenvolvida, está no eixo PAs, sendo o primeiro módulo pelo qual os estudantes de-

5 O setor trabalha com a denominação módulos para os componentes pedagógicos que compõem a matriz curricular do curso, não havendo disciplinas. vem se aproximar do universo acadêmico e universitário, do tema da construção/produção do conhecimento e a questão do conhecimento científico. Além disso, é um momento de reflexão sobre as suas escolhas e identidade dentro do curso. Ao escolher esse eixo e módulo, especificamente, para realizar o trabalho com trajetórias de vida e narrativas (auto)biográficas dos estudantes, enquanto processo de pesquisa-formação, busco situar esse processo em uma dimensão dupla, como forma de levar os estudantes a exercitarem um processo de significação de suas trajetórias, vivências e escolhas, problematizando os motivos que levaram a escolha do curso, bem como, as referências prévias que eles trazem sobre ser professor e ser professor de Educação Física.

Por outro lado, o intuído foi que os estudantes percebessem as múltiplas possibilidades de produção do conhecimento, compreendendo que o conhecimento científico é uma maneira de entender o mundo, mas não a única e nem isenta de intencionalidades e limites.

$\mathrm{Na}$ formulação do currículo do curso de Educação Física, o eixo dos PAs foi organizado e concebido como um eixo que visa privilegiar a temática da construção do conhecimento sistematizado, articulando os demais saberes oriundos da experiência, do estudo e das aprendizagens nos demais eixos curriculares. Essa compreensão procura reconhecer a necessidade de o processo formativo desenvolver práticas reflexivas que visem à emancipação intelectual dos sujeitos desde o início do currículo. 0 ensinar a estudar e pensar de forma crítica, a pesquisar de diferentes formas e, em diferentes perspectivas de pesquisa, são fundamentais na formação acadêmica, mas historicamente essas práticas eram relegadas ao final dos cursos de formação, ou àqueles que conseguiam se inserir nas práticas de iniciação científica em projetos e grupos de pesquisa. 
A proposição ao construir o curso com um eixo que perpassa todo o currículo, do primeiro ao último semestre, é de garantir que todos estudantes tenham acesso a esses saberes. Assim, o ingressante inicia seu processo de formação no módulo de Introdução aos PAs, seguindo para o que chamamos de PA II, no qual eles ainda trabalham de forma coletiva em um módulo que caminha para definição de um primeiro Projeto individual, que passará a ser escrito no PA III e desenvolvido no PA IV, encerrando um primeiro ciclo formativo. Na continuidade, a partir do PA V e PA VI, os estudantes iniciam um novo ciclo, passando para mediação individual e continuando com desenvolvimento do Trabalho de Conclusão de Curso (TCC) I e II nos últimos semestres do curso.

0 módulo introdutório do eixo PAs, se fundamenta nas experiências vividas pelo docente e em estudos e teoria sobre a formação docente, principalmente, os trabalhos de Tardif et al. (1991), Tardif (2002), e Gauthier (1996), que buscam a compreensão dos processos de formação dos professores e seus saberes profissionais.

Tardif (2002), a partir de uma ampla investigação, constrói algumas categorias importantes para a definição dos saberes profissionais docentes. Segundo ele, os saberes docentes, tais como são mobilizados e construídos em situações de trabalho, são: temporais; plurais e heterogêneos; personalizados e situados; e carregam consigo as marcas do seu objeto, que é o ser humano.

Se os saberes dos professores são construídos ao longo de uma trajetória de vida e profissional, é fundamental que essa trajetória, que não começa somente na graduação, seja pensada e entendida como parte da formação dos sujeitos, levando a eles próprios perceber as relações e escolhas feitas ao longo desse processo, bem como, possam construir um projeto profissional e de vida de maneira mais consciente.
Dessa forma, também entendemos que, sendo os saberes situados e personalizados, ou seja, marcados e possuindo as marcas do sujeito que o produz, a formação inicial precisa fomentar e dar ferramentas para que os professores saibam como pesquisar, como refletir, como sistematizar seus saberes, em diferentes perspectivas e dimensão de produção de conhecimento, sendo a investigação e documentação narrativa, uma possibilidade de caminho/estratégia possível para esse pesquisar.

E além de serem heterogêneos e diversos, são marcados pelo objeto do saber, que são seres humanos, algo que não pode somente ser explicado aos futuros professores, é preciso ser vido por eles, então nada mais natural que propostas de estudos que são construídas por eles e com eles, como os PAs.

Dentro de todo esse conjunto de compreensões, o módulo inicial do curso é propício ao resgate das histórias dos futuros professores, a partir de uma perspectiva (auto)biográfica, possibilitando a reflexão sobre um conjunto de experiências vividas na família, nos processos de socialização ocorridos dentro e fora da escola até o ingresso na universidade.

Esse amálgama de experiências vividas ao longo de uma trajetória escolar precisa ser considerado como elemento da formação inicial, sendo pensada como parte da constituição dos saberes e da identidade dos futuros professores.

\section{Analisando as experiências formativas}

Depois de várias experiências desde 2010, com diferentes turmas, em diferentes momentos, falar de uma turma, ou de um momento em específico é um exercício de reflexão complexo e ao mesmo tempo delicado, pois ao relatar aqui alguns elementos encontrados, temos que lembrar que o que temos é uma visão parcial 
de um processo complexo, mas esse exercício analítico se torna necessário para a melhor compreensão da experiência.

Nosso horizonte é uma fração de uma parte de algo que ainda estamos tateando para entender, ainda assim, a pesquisa/estudo é um processo que se propõem tentar compreender o real a partir de suas partes, lembrando que o todo não é meramente a soma dessas partes, mas conhecendo-as é possível buscar totalizações, ou a compreensão ainda que parcial do real, pois esse é mutável e está em permanente movimento.

Em relação, então, à realidade estudada podemos relatar alguns dados: nos últimos cinco anos, aplicamos a metodologia relatada com seis turmas de diferentes cursos e diferentes composições, num total de, aproximadamente, 200 estudantes. Tomando como referência para uma análise, na turma ingressante de 2015, do curso de licenciatura em Educação Física, de um total de 50 estudantes, 41 responderam os dois instrumentos, a escrita inicial e a segunda escrita.

o primeiro elemento que nos chamou a atenção ao analisar o processo, não só nessa turma, foi a dificuldade dos estudantes, em geral, em escrever sobre suas próprias trajetórias; em muitos casos, percebemos um bloqueio em reconhecer as suas vidas como algo significativo, com passagens que mereciam ser registradas e contadas.

Foram comuns falas como: "por que escrever sobre mim? Não tem nada importante!"; "Não tenho nada interessante para falar sobre mim [...]"; "Minha história não tem nada demais [...]" (Diário de campo do professor, 2015).

Por outro lado, em alguns casos, à medida que avançamos da primeira para a segunda escrita, percebemos uma grande evolução na construção da narrativa, a partir dos entendimentos teóricos e do desdobramento do módulo, percebemos que eles passam a valorizar mais o que já foi vivido, passam e reconhecer algumas de suas certezas e saberes e, ao mesmo tempo, começam a refletir mais sobre a escolha do curso e o que esperam dele. A Estudante F.K./2015 explicita essa percepção na sua narrativa:

[...] a experiência de escrever sobre alguns pontos da minha vida foi bem interessante, pois não costumo parar para pensar no que aconteceu e no que eu espero para o futuro e essa prática também me ajudou a perceber os conceitos e aprendizagens que estou levando em minha vida nos aspectos profissional e pessoal. (Estudante F.K/2015)

Ao problematizar os resultados que sistematizamos coletivamente, buscamos provocar nos estudantes a necessidade de definirmos projetos de formação, com objetivos a serem alcançados, dando sentido ao curso que estão realizando e provocando a construção e/ou fortalecimento da autonomia, para que escoIham temas que lhes interessem e façam parte dessa formação, assim como, ressignifiquem os diferentes saberes trabalhados no curso a partir dos seus projetos profissionais e de vida.

A primeira escrita, ainda tímida e resumida, foi o ponto de partida para passarmos à segunda proposta de escrita ampliada; para esse processo, foram utilizadas diversas estratégias provocativas para ampliação da narrativa, entre eles, dinâmicas em grupo, filmes, imagens, entre outras. Dentre essas estratégias/instrumentos, uma tem sido usada de forma recorrente, um roteiro provocativo com itens que balizam a reescrita da trajetória.

Esse roteiro provocativo está organizado na forma de um conjunto de citações que remetem para momentos, locais e sujeitos importantes para compreensão da trajetória dos acadêmicos e as motivações que levaram a escolha do curso. Ele não é um instrumento fechado que deve ser respondido, mas uma provocação para lembrar desses elementos. 
Abaixo um exemplo deste instrumento:

Nasci em uma família [...]; A cidade em que nasci era [...] morei em outros lugares [...]; Minha infância foi [...]; Na adolescência fui [...]; As recordações que tenho da Escola [...]; Fui um aluno [...]; Das aulas de Educação Física me lembro [...]; Nessas aulas era um aluno [...]; Minhas atividades preferidas de lazer são [...]; Sempre pratiquei esportes/ginástica, o que mais gosto é [...]; Hoje faço [...]; E o que mais gosto é [...]; Escolhi este curso por [...]; Ao longo do curso pretendo [...]; Quando me formar espero [...] gostaria de [...]; E depois de tudo, o que gostaria de dizer é [...]

Lembre-se que esses pontos são propostas e provocações, não precisam ser seguidas em ordem, nem respondidas como perguntas, procure criar a sua história com 'floreios e devaneios' para que a história contada, quando escrita seja ainda melhor que o vivido! (Referência ao filme Narradores de Javé). (Roteiro elaborado para o módulo de Introdução aos PAs, primeiro semestre de 2015. (Adaptado a partir de SILVA, 2002, grifos da autor.)

A segunda constatação encontrada, já identificada na literatura e nas pesquisas sobre formação de professores de Educação Física, é que a grande maioria dos estudantes, ao pensarem suas motivações pela escolha do curso, identificam a relação com os temas específicos da Educação Física como motivadores para essa escolha, a relação com o esporte e o gosto pelas atividades fisicas.

Escolhi o curso de Educação Física porque pretendo trabalhar com as crianças e é o esporte é o que elas mais gostam nas aulas de Educação Física (Estudante P.A./2015).

Estou fazendo esse curso, tanto por querer continuar um projeto com jovens atletas, tanto pelo prazer de poder treinar e levar para os jogos pequenos enxadristas [...] (Estudante S.E./2015).

Escolhi a Educação Física por amar esportes e por gostar de ensinar, sempre quis ser professor [...] (V.G. 12/2015)
Alguns estudantes, no caso dessa turma de 2015, identificam também a afinidade com a docência, mas em número menor, outros encontram-se indecisos sobre as motivações da escolha, às vezes, influência familiar, outras a falta de identidade com outros cursos oferecidos.

[...] foram meus irmãos que me convenceram a prestar vestibular. A princípio, o curso seria o de ciências, pois era o menos concorrido e como as aulas eram no período noturno se encaixou nas minhas expectativas [...] (Estudante B. R./2015).

[...] escolhi ser professor ao invés de dentista quando tive essa opção. (Estudante C.E./2015)

[...] escolhi fazer o curso de EF para melhorar o meu trabalho [na educação infantil] com as crianças e futuramente atuar em outras etapas da Educação (Estudante F.K./2015).

Considerando nossos objetivos de formação, o dado em si não se torna o mais importante, mas a ressignificação que os próprios estudantes fazem ao parar para pensar sobre o que os motivou a escolher o curso, esse tem sido o processo mais importante, considerando a necessidade da construção de uma identidade profissional por parte deles.

No processo de sistematização, trabalhamos com algumas categorias iniciais, a infância, a escola, os professores de Educação Física, o esporte e a escolha do curso. Em relação à infância, no grupo de estudantes de 2015, nos chamou a atenção o aspecto lúdico e de liberdade que essa etapa e suas vivências apresentaram, ao mesmo tempo, poucos ou quase nenhum dos futuros professores relaciona a infância, os jogos, as brincadeiras como um espaço formativo.

[...] minha infância foi divertida, brinquei muito na rua, do futebol de golzinho ao bete-ombro (Estudante S.F./2015).

[...] passava o dia todo no campo jogando bola, ou na rua, brincando de tudo que nossa cria- 
tividade nos permitia [...] (Estudante V.G/2015).

[...] minha infância foi bem divertida, por que morar em uma ilha é uma aventura para uma criança (Estudante S. L./2015).

Em relação à escola, na turma em questão, as falas demonstraram uma forte ligação afetiva com o espaço da escola, sendo percebido como um tempo/espaço de boas recordações. A maioria apresentava memórias positivas, lembranças das amizades dos aprendizados. Os professores também tiveram um papel importante para eles, alguns apresentavam ligações familiares com professores, mais um fator que levou a escolha do curso.

As recordações que tenho da escola são boas, tive muitos amigos, muitas experiências diferentes, sempre fui uma aluna dedicada[...] (Estudante S.L./2015).

[...] da escola tenho excelentes lembranças, desde as séries iniciais, pois tive como uma de minhas professoras, minha querida mãe, não por ser minha mãe, mas porque aprendi e continuei aprendendo com ela (Estudante C.L./2015).

Nasci em uma família com predominância no Magistério. Meu bisavô, meu avô e avó paternos foram professores e diretores de ensino [...] (Estudante S.F/2015).

Por fim, o Esporte apresenta-se como a maior referência para a escolha do curso, seja como uma prática prazerosa, lúdica e de lazer, ou como, uma experiência competitiva, através da participação de jogos escolares, competições municipais e estaduais, na escola, ou fora dela, em projetos e escolas de modalidades específicas.

[...] minha atividade preferida de lazer é jogar vôlei e futebol [...] (Estudante P.A./2015).

[...] na adolescência, me envolvi muito com os esportes, da 50 até a 8o série, na época participei todos os anos dos jogos escolares [...] (Estudante B.E./2015).

[...] aos 10 anos troquei de escola e lá comecei a me interessar por esportes, entrei para o time de futsal da escola e para o time de xadrex [...] (Estudante P. D./2015).

Em se tratando de esportes, basicamente gosto de todas as modalidades, com grande preferência para o futebol [...] (Estudante N.F./2015).

\section{Consideração finais, para novas reflexões}

0 trabalho que descrevo neste artigo se apresentou como um processo de pesquisa-formação. Acredito que com o decorrer das atividades, das dinâmicas desenvolvidas para a construção, documentação e análise das narrativas (auto)biográficas dos estudantes, consegui alcançar os objetivos iniciais propostos, problematizando os estudantes na busca de sentidos e significados em suas próprias trajetórias de vida, para a escolha do curso, construção de referências sobre as concepções de escola, ensino, professor e a identificação de temas de interesse dentro do curso para possíveis projetos de formação.

Ao refletir sobre a experiência pedagógica desenvolvida com a utilização das narrativas (auto)biográficas, observo o quanto essa proposta pode ser significativa na construção da identidade profissional. Ao narrarem-se, contando suas histórias, suas escolhas, motivações e experiências anteriores com a Educação Física, os estudantes vão percebendo as relações e opções que os levaram até o curso e quais suas afinidades com os conteúdos e temas do campo de conhecimento da Educação Física.

Nesse movimento, percebo que os conteúdos trabalhados se tornam mais significativos, passam a ter mais sentido, levando a aprendizagens mais efetivas, pois são desenvolvidos no diálogo com as próprias memórias e experiências que os estudantes trazem. Do ponto de vista da perspectiva da docência, em muitos 
momentos os estudantes passam a relacionar o que é discutido em sala de aula com as suas vivências escolares anteriores e os diferentes modelos de professores e ensino que tiveram.

Por outro lado, enquanto processo de pesquisa, os elementos encontrados e as sistematizações desenvolvidas têm contribuído com referências importantes sobre o perfil dos estudantes e as representações que trazem sobre o curso e a carreira profissional, dados que colaboram para a continuidade do processo de formação e com o planejamento de ensino.

Considerando os dados encontrados a partir das narrativas dos estudantes, pude perceber as principais motivações que levaram a escolha do cursos de licenciatura em Educação Física, a identidade com o esporte e as atividades fisicas, o interesse de alguns pela docência, a importância do brincar na infância, as experiências em equipes escolares e a referência dos professores de Educação Física que tiveram durante a escolarização, foram algumas das constatações importantes que obtivemos nessa turma.

Por fim, reforço a importância e a potencialidade de trabalharmos como as narrativas (auto)biográficas de formação, valorizando e reconhecendo o papel formativo do resgate da subjetividade, sendo um passo para a possivel construção de uma poética do fazer docente para além do predomínio de uma racionalidade estritamente técnica.

\section{Referências}

ABRAHÃO, Maria Helena Menna Barreto. Pesquisa (Auto)Biográfica - Tempo, Memória e Narrativas. In: ABRAHÃO, Maria Helena Menna Barreto (Org.). A aventura (auto)biográfica: teoria e empiria. Porto Alegre: EDIPUCRS, 2004. p. 201-224.

ABRAHÃO, Maria Helena Menna Barreto. Intencionalidade, reflexividade, experiência e identidade em pesquisa (auto)biográfica: dimensões epistemo -empíricas em narrativas de formação. In: BRAGAN-
ÇA, Inês Ferreira de Souza; ABRAHÃO, Maria Helena Menna Barreto; FREREIRA, Marcia Santos. (Orgs.). Perspectivas epistêmico-metodológicas da pessoa (auto)biográfica. Curitiba: CRV, 2016. p. 29-50.

BACHELARD, Gaston. A intuição do instante. Campinas, SP: Verus Editora, 2007.

BONDÍA, Jorge Larrosa. Notas sobre a experiência e o saber de experiência. Revista Brasileira de Educação. Rio de Janeiro, ANPEd, n. 19, p. 20-28, Abr. 2002. Disponivel em: https://www.scielo.br/pdf/rbedu/ n19/n19a02.pdf. Acessado em: 30 mar. 2019.

BORGES, Jorge Luis. Ficcciones. Barcelona, Espanha: Alianza Editorial S.A., 1998.

CHARLOT, Bernard. Da relação com o saber: elementos para uma teoria. Porto Alegre: Artmed, 2000.

FERRAROTTI, Franco. Sobre la autonomia del método biográfico. In: MARINAS, José Miguel; SANTAMARINA, Cristina (Org.) La História Oral: métodos y experiências. Madrid: Editorial Debate, 1993. p. 121 -128.

GAUTHIER, Clermont et al. Por uma teoria da pedagogia: pesquisas contemporâneas sobre o saber docente. ljuí: Ed. Unijuí, 1998.

JOSSO, Marie-Christine. História de vida e projeto: a história de vida como projeto e as "histórias de vida" a serviço de projetos. Educação e Pesquisa. São Paulo, FEUSP, v. 25, no 2, São Paulo, FEUSP, Dec. 1999. Disponivel em: http://www.scielo.com.br. Acesso em: 20 set. 2015.

JOSSO, Marie-Christine. Experiências de vida e formação. São Paulo, SP: Ed. Cortez, 2004.

MATURANA, Humberto R. Emoções e linguagem na educação e na política. Belo Horizonte: Ed. UFMG, 2002.

Ministerio de Educación Ciencia y Tecnología de la Nación. La documentación narrativa de experiencias pedagógicas. Una estrategia para la formación de docentes. Buenos Aires, 2005. Disponivel em: https://www.unrc.edu.ar/unrc/academica/pdf/libronarrac1.pdf. Acesso em: 10 mai. 2018.

SILVA, Marcelo Silva. As aventuras e desventuras dos alunos da ESEF/UFPel: um olhar sobre a formação 
do professor de Educação Física. 2002. 102f. Dissertação (Mestrado em Educação) Programa de Pósgraduação em Educação, Faculdade de Educação, Universidade Federal de Pelotas, Pelotas-RS, 2002.

SUÁREZ, Daniel H. La Documentación Narrativa de Experiencias Pedagógicas. La Indagación-Acción del Mundo Escolar para la Reconstrucción de la Memoria Pedagógica de los Docentes. In: VII Red Estrado - Seminário de la Red de Estudios sobre Trabajo Docente, 2008, Buenos Aires. Anais... Buenos Aires: Red Estrado, 2008. v. 1. p. 01-21. Disponivel em: http:// www.fae.ufmg.br/estrado/cdrom_seminario_2008/ textos/ponencias/Ponencia\%20Daniel\%20Su\%C3\%A1rez.pdf. Acesso em: 10 mai. 2018.

SOUSA SANTOS, Boaventura de. Um discurso sobre as ciências. 70 ed. Porto: edições afrontamentos, 1995.

SOUSA SANTOS, Boaventura de. Para um novo senso comum: a ciência, o direito e a política na transição paradigmática. 4a ed. São Paulo: Cortez, 2002.

TARDIF, Maurice et al. Os Professores Face ao Saber: esboço de uma problemática do saber docente. Teoria \& educação, Porto Alegre, no 4, p. 215-233, 1991.

TARDIF, Maurice. Saberes docentes e formação pro-

fissional. Petrópolis, RJ: Vozes, 2002.

VENÂNCIO, Luciana; SANCHES NETO, Luiz. A relação com o saber em uma perspectiva (auto)biográfica na Educação Física escolar. Revista Brasileira de Pesquisa (Auto)Biográfica, Salvador, BIOgraph, v. 04, no 11, p. 729-750, maio/ago. 2019. Disponivel em: https://www.revistas.uneb.br/index.php/rbpab/article/view/4366. Acesso em: 10 abr. 2019.

Recebido em: 20.06.2019 Revisado em: 05.01.2020 Aprovado em: 31.05 .2020

Marcelo Silva da Silva é doutor em Educação pela Universidade do vale do Rio dos Sinos (UNISINOS), com pós-doutorado em Educação pela Universidade Federal de Pelotas (UFPel). Professor do curso de licenciatura em Educação Física, da Universidade Federal do Paraná (UFPR) - Setor Litoral. E-mail: marcelo.ufprlitoral@gmail.com 